\title{
Correction to: Bacillus rugosus sp. nov. producer of a diketopiperazine antimicrobial, isolated from marine sponge Spongia officinalis L.
}

\author{
Dhruba Bhattacharya - Sergio de los Santos Villalobos • Valeria Valenzuela Ruiz • \\ Joseph Selvin · Joydeep Mukherjee
}

Published online: 12 July 2021

(C) Springer Nature Switzerland AG 2021

\section{Correction to:}

Antonie van Leeuwenhoek (2020) 113:1675-1687

https://doi.org/10.1007/s10482-020-01472-9

In the original publication of the article, on the page number 1683 , the strain name "SPB7 $7^{\mathrm{T}}$ " should be removed from the heading "Description of Bacillus rugosus $\mathrm{sp}$. nov. $\mathrm{SPB} 7^{\mathrm{T}}$,
Thus, the correct heading is "Description of Bacillus rugosus sp. nov."

The original article has been corrected.

Publisher's Note Springer Nature remains neutral with regard to jurisdictional claims in published maps and institutional affiliations.

The original article can be found online at https:// doi.org/10.1007/s10482-020-01472-9.

D. Bhattacharya $\cdot$ J. Mukherjee $(\bowtie)$

School of Environmental Studies, Jadavpur University,

Kolkata 700 032, India

e-mail: joydeep.mukherjee@jadavpuruniversity.in

S. de los Santos Villalobos · V. V. Ruiz Instituto Tecnológico de Sonora, 5 de febrero 818 Sur,

C.P. 85000 Col. Centro, Ciudad Obregón,

Sonora, Mexico

J. Selvin

Department of Microbiology, Pondicherry University,

Puducherry 605 014, India 